\title{
Central mechanisms of vascular headaches ${ }^{1}$
}

\author{
J. O. Dostrovsky, ${ }^{2}$ K. D. Davis, ${ }^{3}$ and K. Kawakita ${ }^{4}$ \\ Department of Physiology, University of Toronto, Toronto, Ont., Canada M5S IA8
}

Received June 27, 1990

Dostrovsky, J. O., Davis, K. D., and Kawakita, K. 1991. Central mechanisms of vascular headaches. Can. J. Physiol. Pharmacol. 69: 652-658.

The intracranial blood vessels supplying the dura and brain are innervated by sensory afferents from the trigeminal nerve. These fibers are believed to be responsible for conveying the pain associated with vascular head pain such as migraines. This paper reviews recently published data describing the existence of neurons within the cat trigeminal nucleus and thalamus that respond to electrical stimulation of the middle meningeal artery and superior sagittal sinus. Almost all of these neurons receive convergent input from the facial skin and most of the receptive fields include the periorbital region. On the basis of their cutaneous inputs, most of the neurons are classified as nociceptive. The characteristics of these cerebrovascular-activated neurons are consistent with their role in mediating vascular head pains and with the typical referral of such pains in man to the orbital region. This paper also presents preliminary results of recordings from rat trigeminal ganglion neurons activated by electrical stimulation of the middle meningeal artery and sagittal sinus. The latencies of activation of these neurons are indicative of conduction in slowly conducting myelinated axons and in unmyelinated axons. Some of the neurons could also be activated by mechanical stimuli applied to the vessels.

Key words: headache, pain, trigeminal system, somatosensory, thalamus.

Dostrovsky, J. O., Davis, K. D., et Kawakita, K. 1991. Central mechanisms of vascular headaches. Can. J. Physiol. Pharmacol. $69: 652-658$.

Les vaisseaux sanguins intra-craniens irriguant la dure-mère et le cerveau sont innervés par des afférences sensitives du nerf trigéminal. Ces fibres seraient responsables de la transmission de la douleur associée à la céphalée vasculaire, telle la migraine. Cet article révise des données récentes décrivant l'existence, dans le noyau trigéminal et le thalamus du chat, de neurones qui répondent à une stimulation électrique de l'artère méningée moyenne et du sinus longitudinal supérieur. La très grande majorité de ces neurones reçoit un influx convergent facial, et la plupart des champs récepteurs se situent dans la région périorbitaire. Compte tenu de leurs influx cutanés, la plupart des neurones sont classés comme nociceptifs. Les caractéristiques de ces neurones activés au niveau cérébro-vasculaire sont en accord avec leur rôle de médiateurs de céphalées vasculaires et avec l'irradiation typique de telles douleurs à la région orbitaire chez l'humain. Cet article présente aussi les résultats préliminaires d'enregistrements de neurones ganglionnaires trigéminaux de rats, activés par une stimulation électrique de l'artère méningée moyenne et du sinus longitudinal. Les latences d'activation de ces neurones indiquent l'existence d'une conduction dans les axones myélinisés de conduction lente et dans les axones amyélinisés. Certains des neurones pouvaient aussi être activés par des stimuli mécaniques appliqués aux vaisseaux.

Mots clés : céphalée, douleur, système trigéminal, somesthésique, thalamus.

[Traduit par la rédaction]

\section{Introduction}

The brain is not innervated by nociceptors and thus electrical or mechanical stimulation of the brain, even at tissue-damaging intensities, does not result in pain (except occasionally when stimuli are delivered to the spinothalamic tract and parts of thalamus) (Tasker et al. 1982). However, the pioneering studies of Ray and Wolff (1940) and Penfield and McNaughton (1940), in particular, clearly identified the existence of pain-sensitive structures within the cranium. Electrical, mechanical, and thermal stimulation of the proximal segments of intracranial arteries (pial arteries) and the dural blood vessels results in pain of a headache-like quality (Dalessio 1980b; Ray and Wolff 1940; Penfield and McNaughton 1940) and this pain is usually referred to the forehead. It is generally assumed that the pain of migraine and cluster headaches and that some-

${ }^{1}$ This paper was presented at the XIIth International Symposium of the Centre de recherche en sciences neurologiques, Université de Montréal, called Chronic Musculoskeletal Pain, held in Montréal, Qué., May 24-25, 1990, and has undergone the Journal's usual peer review.

${ }^{2}$ Author for correspondence.

${ }^{3}$ Present address: Dept. of Neurosurgery, John Hopkins University, Meyer 7-113, Baltimore, MD 21205, U.S.A.

${ }_{4}^{4}$ Present address: Dept. of Physiology, Meiji College of Oriental Medicine, Hiyoshi-cho Funai-gun, 629-03 Kyoto, Japan. times resulting from strokes, aneurysms, and arteriovenous malformations result from activation of nociceptors innervating the pial and dural vessels, and hence these pains are frequently termed vascular headaches (Moskowitz et al. 1987; Dalessio 1980a).

Although it has been assumed for many years that the major sensory innervation of the intracranial vessels was via the trigeminal (V) nerve, it is only in recent years that the details of this innervation have been elucidated. It is now known that almost all of the sensory fibers innervating the pial and dural vessels originate in the Vth nerve and most of the cell bodies of these axons are located in the ophthalmic division of the $V$ th ganglion (O'Connor and Van der Kooy 1986; Mayberg et al. 1984; Arbab et al. 1986; Andres et al. 1987; Simons and Ruskell 1988). The cell bodies of sensory afferents innervating the posterior fossa and basilar arteries are located in the C1-C3 dorsal root ganglia (Keller et al. 1985; Saito and Moskowitz 1989). A number of studies have utilized doublelabeling techniques and have failed to find evidence for collateral innervation of vessels and skin (McMahon et al. 1985; O'Connor and Van der Kooy 1986). However, there is evidence that individual cerebrovascular axons can innervate several vessels including both pial and dural vessels ( $\mathrm{O}^{\prime} \mathrm{Connor}$ and Van der Kooy 1986). The sensory afferents innervating the cerebrovasculature, like nociceptive afferents innervating other structures, tend to have small cell bodies, and many con- 
tain peptides such as substance $P$ (SP) and calcitonin gene related peptide (CGRP) (O'Connor and Van der Kooy 1986; Liu-Chen et al. 1984; Suzuki et al. 1989a, 1989b). However, there are differences between cutaneous and cerebrovascular nociceptors, as suggested by the recent findings showing that there is a much higher percentage of neurons containing CGRP in cerebrovascular nerves than in cutaneous nerves (O'Connor and Van der Kooy 1988).

There is little doubt that nociceptors innervating the intracranial vessels play a major if not exclusive role in mediating headaches classified as migraines and cluster headaches; however, there is as yet no universally accepted hypothesis of the underlying mechanisms that result in the activation of these nociceptors (Goadsby and Lance 1988; Moskowitz et al. 1988; Moskowitz et al. 1987; Raskin 1988). It is clear from numerous studies that such headaches are frequently accompanied by disturbances in the cranial circulation. A popular hypothesis for many years has been that the final step in activation of the nociceptors is as a result of vasodilatation and thus stretching of nociceptors within the walls of the vessels (Wolff 1963). However, other hypotheses have suggested that disturbances in circulation are not the direct cause of the pain although they may exacerbate it. Moskowitz has proposed that neurogenic inflammation may play a prominent role in vascular headaches (see review by Moskowitz et al. 1989). This hypothesis has been greatly strengthened by recent studies of sensitization of nociceptors innervating other regions and in particular by recent studies on the effects of inflammation of muscle and joints on nociceptors (Guilbaud 1988; Schaible and Schmidt 1988). It is becoming increasingly clear from many of these studies on primary afferents that SP and probably other peptides such as CGRP are released from small diameter sensory afferents as a result of depolarization of the terminals produced by an initiating (noxious) stimulus and by antidromic invasion of impulses originating in other collaterals. These released peptides act on the surrounding tissue and on the nerve terminals to induce inflammation and sensitization of the terminals (Fields 1987; Guilbaud 1988; Levine et al. 1988; Holzer 1988). Some of the actions of SP that have been identified are vasodilatation and plasma extravasation with consequent increases in the levels of bradykinin as well as release of histamine from mast cells and 5-hydroxytryptamine from platelets. Moskowitz has proposed that these steps occur also in the cerebrovasculature and give rise to prolonged activation and sensitization of cerebrovascular nociceptors and hence to pain. Moskowitz has recently obtained data showing that SP is indeed released from the dura following electrical- or capsaicin-induced activation of the $\mathrm{V}$ th nerve (Markowitz et al. 1987). He has also provided some interesting data showing that the ergot drugs, drugs frequently used in the treatment of migraines, block plasma extravasation induced by electricalor capsaicin-induced excitation of the Vth nerve but not by direct application of SP to the vessel, thus suggesting that ergots prevent release of SP from the nerve terminals (Saito et al. 1988). These recent findings suggest that the clinical effectiveness of the ergots may be due to their reduction of neurogenic inflammation induced by SP release rather than by their action to constrict the vessels as usually assumed. There are obviously many very complicated interactions taking place in the cerebral vessels and much more data must be collected before a reasonable explanation of the pathogenesis of vascular headaches can be made.

During the past few years our group has begun investigating the neural mechanisms underlying vascular headaches. These studies have concentrated on the trigeminal (V) nucleus and thalamus in the cat and have examined the response characteristics of neurons in these regions to stimulation of the middle meningeal artery (MMA) and superior sagittal sinus (SS) (Davis and Dostrovsky 1986; Davis and Dostrovsky 1988a$1988 d$ ). These findings will be briefly reviewed in this paper. Similar findings have also been reported by Strassman and colleagues for the V subnucleus caudalis (Strassman et al. 1986) and by Lambert's group (Angus-Leppan et al. 1989) for thalamus. The latter group has also reported the existence of cerebrovascular-activated neurons in the upper cervical spinal cord (Angus-Leppan et al. 1989). We will also briefly describe our preliminary data on the responses of primary afferent neurons innervating the MMA and SS in the rat.

\section{Methods}

Experiments were performed on cats of either sex (CNS recordings) and rats (Vth ganglion recordings). Details of the surgical and recording procedures in cats have been described previously (Davis and Dostrovsky 1986, 1988a-1988c). Briefly, cats were anesthetized with either pentobarbital or $\alpha$-chloralose and rats with a chloralose-urethane mixture (see Chiang et al. 1989). Throughout the experiment, mean arterial pressure, expired $\mathrm{CO}_{2}$, and rectal temperature were monitored and maintained within their physiological range. When required, animals were paralyzed with Flaxedil (gallamine triethiodide) and artificially ventilated. The animal's head was secured in a stereotaxic frame and a craniotomy was performed to allow placement of a recording electrode in the ipsilateral Vth ganglion $(\mathrm{Vg})$, subnuclei oralis/interpolaris (Vo/Vi), or the contralateral thalamus and to expose the MMA and SS. The neck muscles were dissected away and the dura removed to expose the obex and caudal medulla for recording in the V subnucleus caudalis (Vc). Pairs of silver ball stimulating electrodes were placed in contact with the MMA and SS. In three of the cat experiments, a 30-gauge needle was inserted into the rostral SS and secured to the skull with cement to facilitate intrasinus injections of bradykinin.

Extracellular single unit recordings of $\mathrm{V}$ and thalamic neurons were made with either tungsten or glass microelectrodes (tungsten for all ganglion recordings). Cells that responded to electrical stimulation of the MMA and (or) SS (1-3 pulses, $0.1-0.5 \mathrm{~ms}$ duration, $<16 \mathrm{~mA}, 0.2-0.3 \mathrm{~ms}$ interpulse interval, $1-2 \mathrm{~Hz}$ ) were studied in detail. In some cases, mechanical, thermal, and chemical stimuli were applied to the vasculature. The mechanical stimuli consisted of tugging, stretching, or applying pressure to the vessels. A radiant heat source was used to apply thermal stimuli to the vessels. To study chemosensitivity of vascular receptors, a small amount $(2.5 \mu \mathrm{g})$ of bradykinin was applied topically to the MMA or SS. Alternatively, in some cases, a small amount of bradykinin or saline (approx. $10 \mu \mathrm{g}$ in $0.1 \mathrm{~mL}$ ) was injected into the SS.

When possible, vascular-activated cells were also examined for excitatory input from the facial skin and cornea. Peripheral receptive fields (RFs) were determined by applying various mechanical stimuli (brush, pressure, pinch, etc.) and radiant heat to the facial area. Cells receiving facial inputs were classified as either low threshold mechanoreceptive (LTM), wide dynamic range (WDR), or nociceptive specific (NS) based on their response profile to non-noxious, and (or) noxious mechanical stimuli (Davis and Dostrovsky 1988b). Electrolytic lesions were made at selected recording sites for subsequent histological verification.

\section{Results}

Vth ganglion (preliminary findings)

Recordings were obtained from 46 cells in the $\mathrm{Vg}$ of 16 rats. Nineteen of these cells had receptive fields on the face and were included for comparison purposes (see below). Of 
A

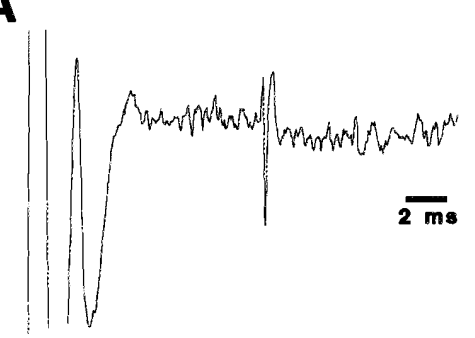

$\mathbf{B}$

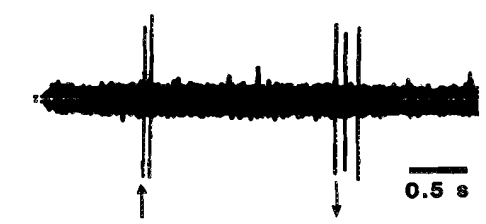

C

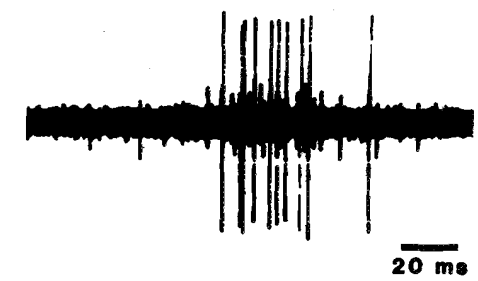

FIG. 1. Responses of three neurons in the rat Vth ganglion. (A) Oscilloscope trace showing response to electrical stimulation of the superior sagittal sinus (SS). (B) Response to mechanical stimulation of the SS (lifting and releasing sinus by means of a thread passing around the sinus). Arrowheads indicate occurrence of the stimuli. (C) Response to radiant heating of the dura in the vicinity of the MMA. Temperature was not quantified but was judged to be noxious on the basis of similar illumination on the skin of the investigator.

the remaining 27 cells, 14 were activated by electrical stimulation of the MMA and 13 by electrical stimulation of the SS. One of the latter cells appeared to be activated from a small area of ophthalmic skin in addition to the SS. None of the other cerebrovascular-activated cells had receptive fields on the face. On the basis of the recordings from surrounding neurons in the ganglion, most of the cerebrovascular-activated neurons were probably located within the ophthalmic division of the Vg.

Electrically evoked responses typically consisted of a single spike (see Fig. 1A). The mean minimum latencies ( \pm SEM) in response to electrical stimulation were $5.2 \pm 1.4 \mathrm{~ms}$ (range, $0.8-16 \mathrm{~ms}$ ) from MMA stimulation, $5.3 \pm 1.1 \mathrm{~ms}$ (range, $1.1-10 \mathrm{~ms})$ from SS stimulation, and $2.0 \pm 0.4 \mathrm{~ms}$ (range, 1.0-8.1 ms) from the skin. Since the conduction distances to the $\mathrm{Vg}$ from the MMA and SS are approximately 10 and $20 \mathrm{~mm}$, respectively, the presumed mean conduction velocities of the cells activated from the MMA and SS were approximately 2 and $4 \mathrm{~m} / \mathrm{s}$, respectively. Only four of the cells (all MMA-activated cells) had conduction velocities of less than $2 \mathrm{~m} / \mathrm{s}$ and were presumed to be $C$-fibers. The remaining MMA-activated cells and all the SS-activated cells had conduction velocities in the A $\delta$-fiber range.

Some of the Vg cells activated by electrical stimulation of the vasculature were also examined for sensitivity to mechanical stimuli applied to the vessels and most $(80 \%)$ were excited
A

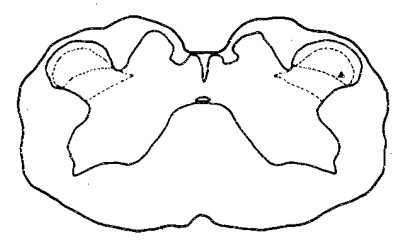

B

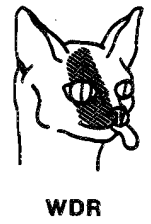

C
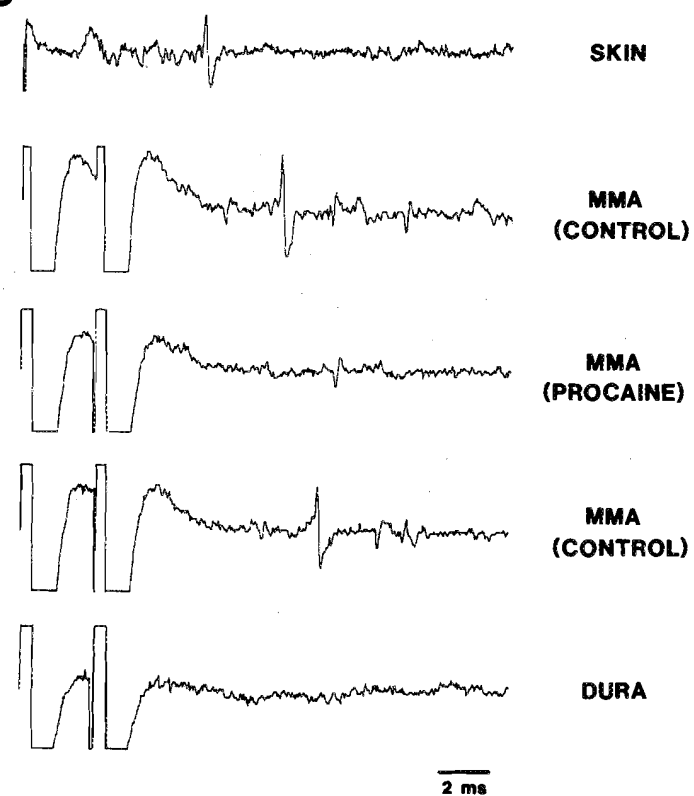

FIG. 2. Responses of a wide dynamic range (WDR) neuron to stimulation of the middle meningeal artery (MMA). (A) Recording site in the V trigeminal subnucleus caudalis. (B) The neuron's cutaneous receptive field (RF). (C) Oscilloscope traces showing responses of the neuron to electrical stimulation of the skin (RF) and the MMA, block of the responses to MMA stimulation during topical application of procaine to the artery, recovery (control) from procaine block, and lack of activation when stimulation was delivered to dura close to the MMA. (Reproduced with permission from Davis and Dostrovsky 1988b.)

(see Fig. 1B). Mechanically evoked responses typically consisted of a burst discharge at the onset of the stimulus. One of three cells tested was excited by radiant heating (presumed noxious) of the vasculature (see Fig. 1C).

\section{$V$ th spinal tract nucleus}

$\mathrm{A}$ total of 130 neurons in $\mathrm{Vc}$ and 120 neurons in $\mathrm{Vo} / \mathrm{Vi}$ that were activated by electrical stimulation of the MMA and (or) SS were studied. All neurons were tested for excitation from the MMA but only 43 of the Vc neurons and 86 of the $\mathrm{Vo} / \mathrm{Vi}$ neurons were also tested for SS input. Within Vc, $16 \%$ of the neurons tested for inputs from both vessels responded to MMA stimulation, $65 \%$ to SS stimulation, and $19 \%$ to stimulation of both structures. Figure $2 \mathrm{C}$ shows the response of a neuron in Vc to electrical stimulation of the MMA. Within $\mathrm{Vo} / \mathrm{Vi}, 32 \%$ of the neurons tested for inputs from both vessels responded to MMA stimulation, $40 \%$ to SS stimulation, and $28 \%$ to stimulation of both structures.

The latencies of activation of $\mathrm{Vc}$ and $\mathrm{Vo} / \mathrm{Vi}$ neurons by electrical stimulation of the vasculature were similar (see Fig. 3) and corresponded to conduction velocities of approximately 
A

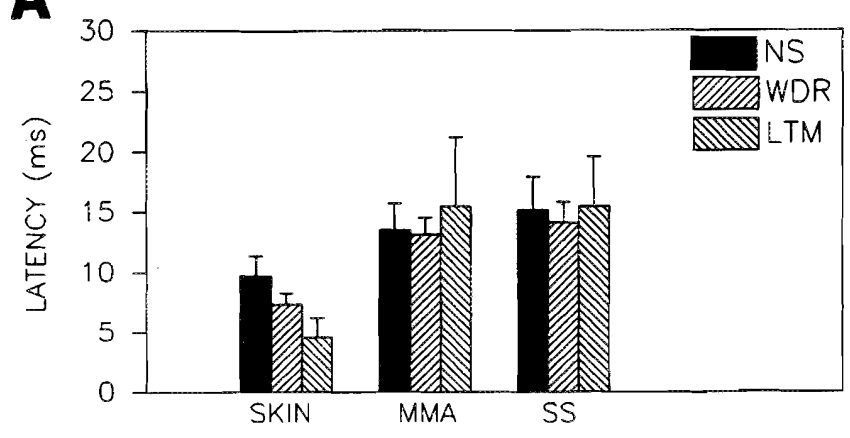

B

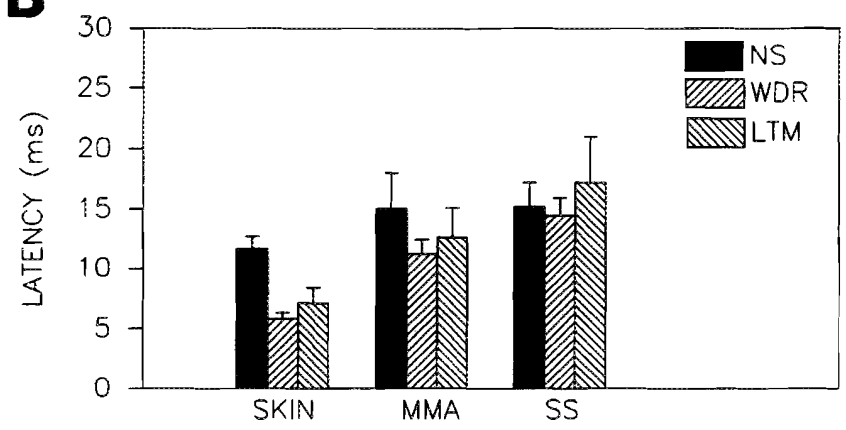

C

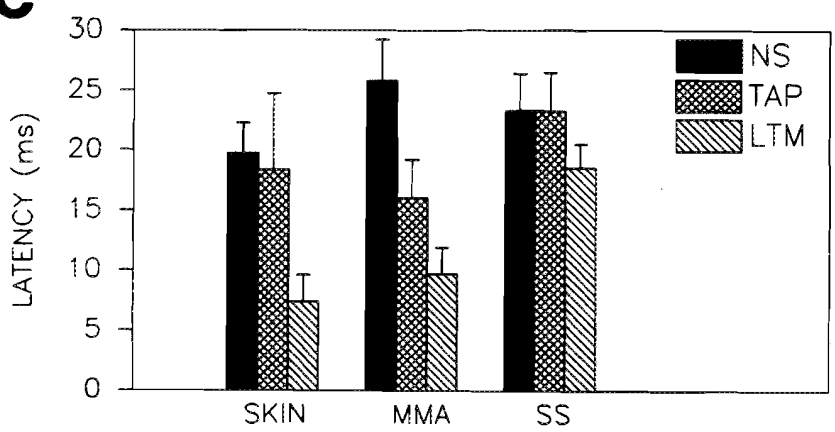

FIG. 3. Mean latencies of activation of neurons in the $\mathrm{V}$ subnucleus caudalis (Vc), $\mathrm{V}$ subnuclei oralis/interpolaris (Vo/Vi), and thalamus in response to stimulation of the middle meningeal artery (MMA), superior sagittal sinus (SS), and skin according to cell type. (A) Neurons in $\mathrm{Vc}$; (B) neurons in $\mathrm{Vo} / \mathrm{Vi}$; $(\mathrm{C})$ neurons in thalamus.

$5 \mathrm{~m} / \mathrm{s}$ (MMA) and $4 \mathrm{~m} / \mathrm{s}$ (SS), indicative of activation by $A \delta$-fibers. The latencies of activation of these neurons from stimulation within their facial receptive fields (RFs) were shorter, especially for the LTM and WDR neurons. In many cases the stimulating electrodes were placed at various positions along the MMA and also on the adjacent dura. It was consistently observed that stimulation of the adjacent dura was ineffective (e.g., Fig. 2C). In general more proximal stimulation sites on the MMA were more effective than distal loci.

Of the vascular-activated cells studied in detail, all but four had cutaneous or corneal RFs. At the level of Vc, $95 \%$ of the RFs involved the ophthalmic region (see example in Fig. 2) and in many cases included the cornea. At the level of $\mathrm{Vo} / \mathrm{Vi}$, two thirds of the RFs were in the ophthalmic region and one third of the RFs involved maxillary and (or) mandibular

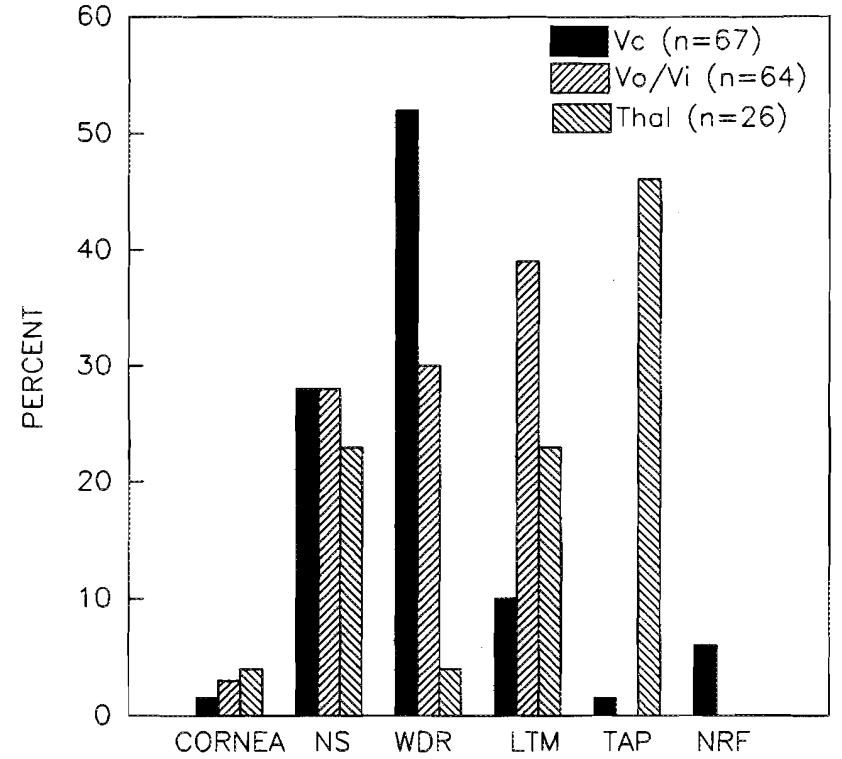

FIG. 4. Incidence of cells in the $\mathrm{V}$ subnucleus caudalis $(\mathrm{Vc}), \mathrm{V}$ subnuclei oralis/interpolaris $(\mathrm{Vo} / \mathrm{Vi})$, and thalamus activated by electrical stimulation of the middle meningeal artery and (or) superior sagittal sinus according to cell type. LTM, low threshold mechanoreceptive; NRF, no cutaneous receptive field found; NS, nociceptive specific; Thal, thalamus; WDR, wide dynamic range.

regions. Most of these $\mathrm{Vc}(87 \%)$ and $\mathrm{Vo} / \mathrm{Vi}$ neurons $(61 \%)$ were classified as nociceptive (i.e., WDR or NS) and the remaining were classified as LTM (Fig. 4). The RFs of NS cells were usually confined to one $\mathrm{V}$ division, whereas more than $50 \%$ of the WDR cells had RFs encompassing two or three $\mathrm{V}$ divisions.

Histological verification of many of the recording sites revealed a clustering of the vascular-activated neurons in the lateral half of laminae III $-\mathrm{V}$ in Vc. However, in $\mathrm{Vo} / \mathrm{Vi}$ the vascular-activated cells were distributed throughout the region, including some in the interstitial nuclei within the Vth tract.

In one series of experiments the cold block technique was used to reversibly alter transmission of activity through Vc (Davis and Dostrovsky 1988d). The results of these experiments indicated that there is both a direct relay of information from the vasculature to $\mathrm{Vo} / \mathrm{Vi}$ neurons and an indirect relay via Vc.

\section{Thalamus}

Multiple penetrations were made through lateral thalamus in the vicinity of the ventroposterior medial nucleus (VPM) to search for neurons activated by electrical stimulation of MMA and SS. Of the 61 neurons studied, $23 \%$ were activated from the MMA, $39 \%$ from the SS, and the remainder from both vessels. The mean latencies of activation of these thalamic neurons by electrical stimulation of the MMA and SS, and their facial cutaneous RFs are shown in Fig. 3C. Unlike the $\mathrm{V}$ neurons that generally responded to vascular stimulation with a single spike, the thalamic neurons usually responded with a burst of $2-5$ spikes. This burst response could be evoked by electrical or mechanical stimulation of the vessels and also by stimulation within the neuron's facial RF.

Of the thalamic neurons examined for the existence of an orofacial RF, all were found to be activated by mechanical stimulation of the orofacial region. These RFs usually involved 
the ophthalmic region and occasionally included the cornea. Approximately two thirds of the neurons activated by both the MMA and the SS had large RFs involving more than one V division, but most of the neurons activated only from the MMA or SS had RFs confined to one V division. Classification of the thalamic neurons based on responses to mechanical stimulation of the face revealed an unusual feature of tap responsiveness for approximately one half of the neurons (Fig. 4). In these cases, the effective stimulus for evoking a response was a sharp, brisk tap to the facial $\mathrm{RF}$. The latencies of activation of these tap-activated neurons were longer than those of LTM neurons and comparable to those of nociceptive neurons (Fig. 3C). The remaining neurons were classified as either NS or LTM (Fig. 4).

\section{Mechanically evoked responses}

Some of the neurons in the $\mathrm{V}$ spinal tract nucleus and the thalamus that were activated by electrical stimulation of the vasculature were also examined for sensitivity to mechanical stimulation of the MMA and SS. The vessels were subjected to stimuli such as tugging, stretching, pressing, or tapping. These mechanical stimuli nearly always evoked a response when applied to the SS (9 of 11 cases) and often evoked activity when applied to the MMA (8 of 14 cases).

\section{Chemically evoked responses}

Sensitivity to bradykinin was examined for $12 \mathrm{~V}$ spinal tract nucleus neurons and three thalamic neurons activated by electrical stimulation of the MMA and (or) the SS (see Davis and Dostrovsky (1988c) for further details). Seven of these $15 \mathrm{neu}-$ rons were found to have chemosensitivity. Bradykinin applied to the MMA activated five of the nine tested neurons, and when applied to the SS activated three of the 11 tested neurons. One neuron responded to bradykinin applied to the MMA and SS. All responsive neurons received nociceptive convergent input from the face, whereas none of the five neurons classified as LTM were activated by bradykinin. Furthermore, all but one of the responsive neurons displayed ongoing background activity but most of the nonresponsive neurons had no spontaneous discharge. Thus, the presence of spontaneous activity and a nociceptive orofacial RF was characteristic of the chemoresponsive neurons.

Typically, responsive neurons began firing at rates above background a few seconds following drug application (see example in Fig. 5). The duration of the effect varied from 20 to $60 \mathrm{~s}$ at which time the cell's activity returned to baseline. The effect of bradykinin varied from a minor discharge to as much as a $300 \%$ increase in background activity.

\section{Discussion}

These electrophysiological studies have provided direct evidence for the existence of neurons within the $\mathrm{V}$ nucleus and thalamus that are activated by stimuli delivered to the dural vessels. It is likely that at least some of these neurons are involved in mediating painful sensations consequent to activation of cerebrovascular sensory afferents for the following reasons: (1) electrical, mechanical, and thermal stimulation of the dural vessels in humans has been reported to elicit only painful sensations (Hardy et al. 1952; Dalessio 1980b; Ray and Wolff 1940; Penfield and McNaughton 1940; Wolff 1963); (2) latencies of activation of $\mathrm{Vg}$ and $\mathrm{V}$ brainstem neurons are consistent with activation of small diameter fibers; (3) some of the neurons were activated by bradykinin, an agent that is well known to activate nociceptors, although not necessarily exclusively (Szolcsanyi 1987; Beck and Handwerker 1974; Kanaka et al. 1985); (4) it is well accepted that nociceptive neurons in the $\mathrm{V}$ subnucleus caudalis are involved in mediating pain in the orofacial region (Sessle 1987; Dubner et al. 1978); (5) there is evidence for an involvement of $\mathrm{V}$ subnuclei oralis and interpolaris, regions where cerebrovascularactivated neurons were found, in nociception (Sessle 1987; Hayashi et al. 1984; Dallel et al. 1988); and (6) the existence of neurons at the thalamic level with response properties similar to those in the $\mathrm{V}$ nucleus implies that at least some of the cerebrovascular-activated neurons in the $\mathrm{V}$ nucleus projected to thalamus, and is also consistent with the observations of Strassman et al. (1986) that some of the cerebrovascular-activated caudalis neurons could be antidromically activated from the thalamus. Furthermore, it is likely that somatosensory nociceptive neurons in thalamus are involved in mediating the affective and sensory aspects of pain (Willis 1985; Price 1988).

One of the characteristic features of the neurons activated by cerebrovascular inputs was the very high incidence of receptive fields that included the periorbital region, findings that are in agreement with those of Strassman et al. (1986). The frequent occurrence of such receptive fields is consistent with the frequent referral of vascular head pains to the periorbital and temple region (Dalessio 1980b; Raskin 1988). The incidence of periorbital RFs in the total population of neurons in the $\mathrm{V}$ nucleus (Hu and Sessle 1989) is much lower than that in the population of neurons activated from the cerebrovasculature. Neurons activated by electrical stimulation of the tooth pulp (Hu et al. 1981) or temporomandibular joint (Broton et al. 1988) also receive convergent inputs from the skin, however, in these cases the incidence of periorbital RFs is not higher than normal.

In almost all cases cells activated from the cerebrovasculature were also activated from the skin. The few cells for which no receptive field was found might have had a receptive field in an inaccessible region (e.g., intraorally) or a very high threshold and a small receptive field that was missed. The convergence of vascular and somatic afferents on the same neurons is consistent with findings of other studies in the $V$ system, spinal cord, and thalamus that examined inputs from muscles, joints, tooth pulp, and visceral organs (Willis 1985; Fields 1987; Broton et al. 1988; Hu et al. 1981; Amano et al. 1986; Sessle et al. 1986). The convergence of cutaneous and cerebrovascular afferents is most likely occurring in the $\mathrm{V}$ nucleus. It is highly unlikely that the convergence was a result of bifurcating peripheral axons, since the anatomical studies (McMahon et al. 1985; O'Connor and Van der Kooy 1986) and our preliminary ganglion recording studies failed to find evidence for a significant population of such primary afferents.

Our finding of neurons in the $\mathrm{V}$ subnuclei oralis and interpolaris that are activated from the vasculature and the fact that a considerable percentage of them received nociceptive convergent inputs from the skin provide further support for a role for these nuclei in nociception (Sessle 1987; Dallel et al. 1988). These findings are comparable to previous electrophysiological studies that reported the existence of neurons in this region activated by noxious cutaneous stimuli (Hayashi et al. 1984) and by stimulation of tooth pulp and muscle nerves, inputs likely to be nociceptive (Hayashi et al. 1984).

This paper has provided the first preliminary report of recordings from cerebrovascular primary afferents and has 

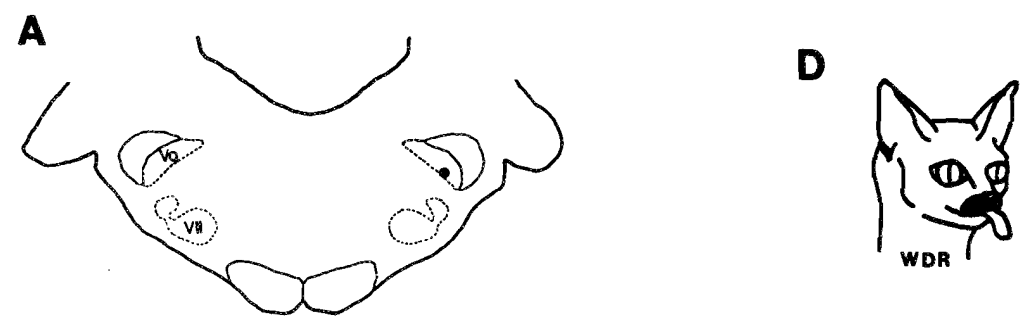

B

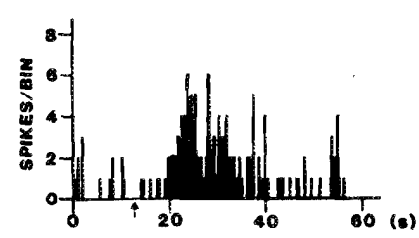

C

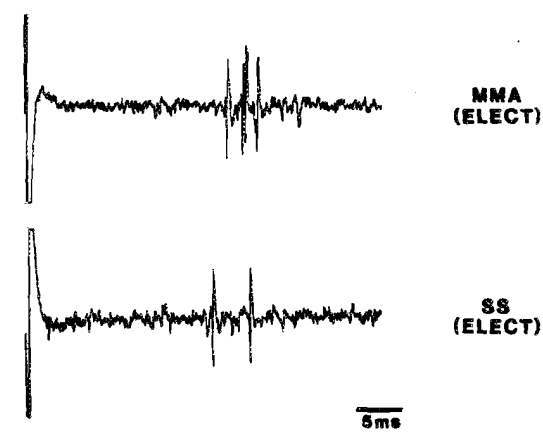

E
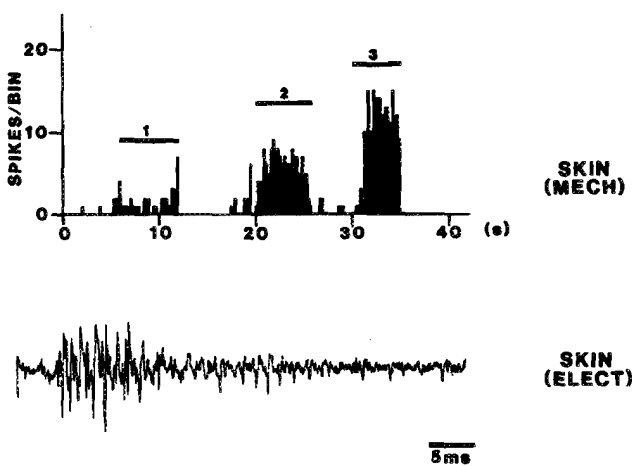

(EKIN

Fig. 5. Responses of a middle meningeal artery (MMA)- and a superior sagittal sinus (SS)-activated V subnucleus oralis neuron. (A) Recording site. (B) Response of the neuron to bradykinin (arrow indicates time of injection). (C) Oscilloscope traces of responses to electrical stimulation of the MMA and SS. (D) Location of the receptive field (RF). (E) Firing-rate histogram (top) showing responses of neuron to increasing intensities of mechanical stimulus (pressure, pinch) applied to the neuron's RF. Bottom trace shows oscilloscope trace of response to electrical stimulation of the RF. (Reproduced with permission from Davis and Dostrovsky 1988c.)

reviewed the recent electrophysiological findings indicating that sensory inputs arising in the dural vessels activate neurons in the $\mathrm{Vc}, \mathrm{Vo} / \mathrm{Vi}$, and thalamus. Many of these neurons also receive nociceptive inputs from the facial skin and cornea and are likely to be involved in relaying the nociceptive inputs from the cerebrovasculature that give rise to vascular head pains. These neurons share many similarities with other $V$ and spinal nociceptive neurons that are activated by deep structures and viscera. The predominant periorbital receptive fields of the cerebrovascular-activated neurons are consistent with the common referral of vascular head pains to the periorbital region.

\section{Acknowledgements}

The authors wish to thank Mary Teofilo for expert technical assistance. This project was supported by grant DE05404 from the U.S. National Institutes of Health.

Amano, N., Hu, J. W., and Sessle, B. J. 1986. Responses of neurons in feline trigeminal subnucleus caudalis (medullary dorsal horn) to cutaneous, intraoral, and muscle afferent stimuli. J. Neurophysiol. 55: $227-243$.

ANDRES, K. H., voN DURING, M., MUSZYNSKI, K., and SCHMIDT, R. F. 1987. Nerve fibres and their terminals of the dura mater encephali of the rat. Anat. Embryol. 175: 289-301.

Angus-Leppan, H., Boers, P., Zagami, A. S., and Lambert G. A. 1989. The cervical spinal cord relays craniovascular input to the thalamus. Soc. Neurosci. Abstr. 15: 470.
Arbab, M. A. R., Wiklund, L., and SvendgaArd, N. A. 1986. Origin and distribution of cerebral vascular innervation from superior cervical, trigeminal and spinal ganglia investigated with retrograde and anterograde WGA-HRP tracing in the rat. Neuroscience, 19: $695-708$.

BECK, P. W., and HANDWERKER, H. O. 1974. Bradykinin and serotonin effects on various types of cutaneous nerve fibres. Pfluegers Arch. 347: 209-222.

Broton, J. G., Hu, J. W., and Sessle, B. J. 1988. Effects of temporomandibular joint stimulation on nociceptive and nonnociceptive neurons of the cat's trigeminal subnucleus caudalis (medullary dorsal horn). J.Neurophysiol. 59: 1575-1589.

Chiang, C. Y., Chen, I. C., Dostrovsky, J. O., and Sessle, B. J. 1989. Inhibitory effect of stimulation of the anterior pretectal nucleus on the jaw-opening reflex. Brain Res. 497: 325-333.

DALESSIO, D. J. (Editor). 1980a. A clinical classification of headache. In Wolff's headache and other head pain. Oxford, New York. pp. 1-23.

- (Editor). 1980b. Pain-sensitive structures within the cranium. In Wolff's headache and other head pain. Oxford, New York. pp. 24-55.

Dallel, R., Raboisson, P., Auroy, P., and Woda A. 1988. The rostral part of the trigeminal sensory complex is involved in orofacial nociception. Brain Res. 448: 7-19.

DAVIS, K. D. , and DostrovsKY, J. O. 1986. Activation of trigeminal brain-stem nociceptive neurons by dural artery stimulation. Pain, 25: $395-401$.

1988a. Properties of feline thalamic neurons activated by stimulation of the middle meningeal artery and sagittal sinus. Brain Res. 454: 89- 100 . 
$1988 b$. Responses of feline trigeminal spinal tract nucleus neurons to stimulation of the middle meningeal artery and sagittal sinus. J. Neurophysiol. 59: 648-666.

$1988 c$. Cerebrovascular application of bradykinin excites central sensory neurons. Brain Res. 446: 401-406.

$1988 d$. Effect of trigeminal subnucleus caudalis cold block on the cerebrovascular-evoked responses of rostral trigeminal complex neurons. Neurosci. Lett. 94: 303-308.

Dubner, R., Sessle, B. J., and Storey, A. T. 1978. The neural basis of oral and facial function. Plenum Press, New York.

FieldS, H. L. 1987. Pain. McGraw-Hill Book Co., New York.

GoADSBY, P. J., and LANCE, J. W. 1988. Brain stem effects on intraand extracerebral circulations. Relation to migraine and cluster headache. In Basic mechanisms of headache. Edited by J. Olesen and L. Edvinsson. Elsevier Science Publishers BV, Amsterdam. pp. $413-427$.

GuILBAuD, G. 1988. Peripheral and central electrophysiological mechanisms of joint and muscle pain. In Proceedings of the Vth World Congress on Pain: Pain Research and Clinical Management. Vol. 3. Edited by R. Dubner, G. F. Gebhart, and M. R. Bond. Elsevier Science Publishers, Amsterdam. pp. 201-215.

HaRdy, J. D., WolfF, H. G. and Goodell, H. 1952. Pain sensations and reactions. Williams and Wilkins, Baltimore.

HaYAShI, H., Sumino, R. and Sessle, B. J. 1984. Functional organization of trigeminal subnucleus interpolaris: nociceptive and innocuous afferent inputs, projections to thalamus, cerebellum, and spinal cord, and descending modulation from periaqueductal gray. J.Neurophysiol. 51: 890-905.

HoLzer, P. 1988. Local effector functions of capsaicin-sensitive sensory nerve endings: involvement of tachykinins, calcitonin generelated peptide and other neuropeptides. Neuroscience, 24: $739-768$.

Hu, J. W., and SesSle, B. J. 1989. Effects of tooth pulp deafferentation on nociceptive and nonnociceptive neurons of the feline trigeminal subnucleus caudalis (medullary dorsal horn). J.Neurophysiol. 61: 1197-1206.

Hu, J. W., Dostroysky, J. O., and Sessle, B. J. 1981. Functional properties of neurons in cat trigeminal subnucleus caudalis (medullary dorsal horn). I. Response to oral-facial noxious and nonnoxious stimuli and projections to thalamus and subnucleus oralis. $J$. Neurophysiol. 45: 173-192.

KanaKa, R., Schaible, H. G., and Schmidt, R. F. 1985. Activation of fine articular afferent units by bradykinin. Brain Res. 327: $81-90$.

Keller, J. T., Saunders, M. C., Beduk, A., and Jollis, J. G. 1985. Innervation of the posterior fossa dura of the cat. Brain Res. Bull. 14: $97-102$

LeVine, J. D., Coderre, T. J., and Basbaum, A. I. 1988. The peripheral nervous system and the inflammatory process. In Proceedings of the Vth World Congress on Pain: Pain Research and Clinical Management. Vol. 3. Edited by R. Dubner, G. F. Gebhart, and M. R. Bond. Elsevier Science Publishers BV, Amsterdam. pp. 33-43.

liv-Chen, L.-Y., Gillespie, S. A., NorregaArd, T. V., and Moskowitz, M. A. 1984. Co-localization of retrogradely transported wheat germ agglutinin and the putative neurotransmitter substance $P$ within trigeminal ganglion cells projecting to cat middie cerebral artery. J. Comp. Neurol. 225: 187-192.

Markowitz, S., Sarto, K., and Moskowitz, M. A. 1987. Neurogenically mediated leakage of plasma protein occurs from blood vessels in dura mater but not brain. J. Neurosci. 7: 4129-4136.

MayberG, M. R., Zervas, N. T., and Moskowitz, M. A. 1984. Trigeminal projections to supratentorial pial and dural blood vessels in cats demonstrated by horseradish peroxidase histochemistry. J. Comp. Neurol. 223: 46-56.

McMahon, M. S., NorregaArd, T. V., Beyerl, B. D., Borges, L. F., and Moskowitz M. A. 1985. Trigeminal afferents to cerebral arteries and forehead are not divergent axon collaterals in cat. Neurosci. Lett. 60: 63-68.
Moskowitz, M. A., Saito, K., Sakas, D. E., and Markowitz, S. 1987. The trigeminovascular system and pain mechanisms from cephalic blood vessels. In Proceedings of the Vth World Congress on Pain: Pain Research and Clinical Management. Vol. 3. Edited by R. Dubner, G. F. Gebhart, and M. R. Bond. Elsevier Science Publishers, Amsterdam. pp. 177-185.

Moskowitz, M. A., Henrikson, B. M., Markowitz, S., and SAITo, K. 1988. Intra- and extracraniovascular nociceptive mechanisms and the pathogenesis of head pain. In Basic mechanisms of headache. Edited by J. Olesen and L. Edvinsson. Elsevier Science Publishers BV, Amsterdam. pp. 429-437.

Moskowrtz, M. A., Buzzı, M. G., Sakas, D. E., and Linnik, M. D. 1989. Pain mechanisms underlying vascular headaches. Rev. Neurol. (Paris), 145: 181- 193.

O'CONNOR, T. P. and VAN DER KoOY, D. 1986. Pattern of intracranial and extracranial projections of trigeminal ganglion cells. J. Neurosci. 6: $2200-2207$.

- 1988. Enrichment of a vasoactive neuropeptide (calcitonin gene related peptide) in the trigeminal sensory projections to the intracranial arteries. J.Neurosci. 8: 2468-2476.

Penfield, W., and MCNaughton F. L. 1940. Dural headache and innervation of the dura mater. Arch. Neurol. Psychiatry, 44: 43-75.

Price, D. D. 1988. Psychological and neural mechansims of pain. Raven Press Ltd., New York.

Raskin, N. H. 1988. Headache. 2nd ed. Churchill Livingstone, New York.

RAY, B. S., and WolfF, H. G. 1940. Experimental studies on headache: pain sensitive structures of the head and their significance in headache. Arch. Surg. 41: 813-856.

SAITo, K., and Moskowirz, M. A. 1989. Contributions from the upper cervical dorsal roots and trigeminal ganglia to the feline circle of Willis. Stroke, 20: 524-526.

Sairo, K., Markowitz, S., and Moskowitz, M. A. 1988. Ergot alkaloids block neurogenic extravasation in dura mater: proposed action in vascular headaches. Ann. Neurol. 24: 732-737.

SCHAIBLE, H.-G., and SCHMIDT, R. F. 1988. Time course of mechanosensitivity changes in articular afferents during a developing experimental arthritis. J. Neurophysiol. 60: 2180-2195.

SESSLE, B. J. 1987. The neurobiology of facial and dental pain: present knowledge, future directions. J. Dent. Res. 66: 962-981.

Sessle, B. J., Hu, J. W., Amano, N., and Zhong, G. 1986. Convergence of cutaneous, tooth pulp, visceral, neck and muscle afferents onto nociceptive and non-nociceptive neurones in trigeminal subnucleus caudalis (medullary dorsal horn) and its implications for referred pain. Pain, 27: 219-235.

Simons, T., and RUSKELL, G. L. 1988. Distribution and termination of trigeminal nerves to the cerebral arteries in monkeys. J. Anat. 159: $57-71$.

Strassman, A., Mason, P., Moskowitz, M., and Maciewicz, R. 1986. Response of brainstem trigeminal neurons to electrical stimulation of the dura. Brain Res. 379: 242-250.

Suzuki, N., Hardebo, J. E., Kahrstrom, J., and OWman, C. 1989a. Galanin-positive nerves of trigeminal origin innervate rat cerebral vessels. Neurosci. Lett. 100: 123-129.

Suzuki, N., Hardebo, J. E., and Owman, C. 1989b. Origins and pathways of cerebrovascular nerves storing substance $P$ and calcitonin gene-related peptide in rat. Neuroscience, 31: 427-438.

SzolCSANY1, J. 1987. Selective responsiveness of polymodal nociceptors of the rabbit ear to capsaicin, bradykinin and ultra-violet irradiation. J. Physiol. (London), 388: 9-23.

TASker, R. R., OrGaN, L. W., and HaWryLYSHYN, P. A. 1982. The thalamus and midbrain of man. A physiological atlas using electrical stimulation. Thomas, Springfield, IL.

Willis, W. D., JR. 1985. The pain system. The neural basis of nociceptive transmission in the mammalian nervous system. In Pain and headache. Edited by P. L. Gildenberg. S. Karger, Basel.

WoLfF, H. G. 1963. Headache and other head pain. Oxford University Press, New York. 